\title{
Селективность глауконита при сорбции катионов металлов из водных растворов в динамических условиях
}

\author{
Вигдорович В.И. ${ }^{1,3}$, Цыганкова Л.Е. ${ }^{2}$, Алехина О.В. ${ }^{2,3}$, \\ Урядникова М.Н. ${ }^{2}$, Шель Н.В. ${ }^{3}$, Зарапина И.В. ${ }^{3}$, Прохоренков В.Д. ${ }^{1}$ \\ ${ }^{I}$ ФГБНУ «Всероссийский научно-исследовательский институт использования техники и нефтепро- \\ дуктов в сельском хозяйстве», Тамбов \\ ${ }^{2}$ ФГБОУ ВО «Тамбовский государственный университет им. Г.Р. Держсавина», Тамбов \\ ${ }^{3}$ ФББОУ ВО «Тамбовский государственный технический университет», Тамбов
}

Поступила в редакцию 13.05.2018 г.

DOI: https://doi.org/10.17308/sorpchrom.2018.18/604

Изучена избирательность сорбции 95\%-го концентрата глауконита при комнатной температуре в динамических условиях по отношению к растворам смесей катионов в двух экспериментальных сериях. В каждой серии сорбцию проводили из однокомпонентного раствора соли с изучаемым катионом и многокомпонентной системы в присутствии солей всех изучаемых катионов в тех же концентрациях одновременно.

В первой серии использован 0.1 мМ сульфатный раствор солей катионов (II) металлов группы железа. Во второй серии - катионы Са(II) и $\mathrm{Mg}$ (II) концентрации 0.125 и $1.56 \cdot 10^{-2}$ ммоль/дм ${ }^{3} \mathrm{Cu}(\mathrm{II})$. В последнем случае концентрация $\mathrm{Cu}(\mathrm{II})$ соответствовала предельно-допустимой для вод культурнобытового назначения. Линейная скорость раствора составляла 0.3 и 0.5 м/ч (ламинарное течение). Высота слоя сорбента -0.5 и 1.5 см. Катионы железа (II) избирательно сорбируются глауконитом, что доказано идентичностью параметров сорбции (зависимость коэффициента сорбции во времени и динамическая емкость сорбента в разные периоды протекания процесса) из одно- и трехкомпонентных растворов. Катионы Со(II) сорбируются только на свободных адсорбционных центрах (АЦ) в отсутствие катионов $\mathrm{Fe}(\mathrm{II})$ и $\mathrm{Ni}(\mathrm{II})$. Они могут выступать в качестве обменных катионов при введении ионов $\mathrm{Fe}(\mathrm{II})$ и $\mathrm{Ni}(\mathrm{II})$. Катионы $\mathrm{Cu}(\mathrm{II})$ сорбируются избирательно на определенных АЦ в присутствии многократно (8 раз) превышающих их концентраций катионов $\mathrm{Ca}(\mathrm{II})$ и $\mathrm{Mg}(\mathrm{II})$. Присутствие ионов $\mathrm{Cu}(\mathrm{II})$, в свою очередь, не влияет на сорбционную способность катионов жесткости.

Ключевые слова: сорбция, глауконит, поток, активный центр, селективность, катионы, железо, кобальт, никель, кальций, магний, медь.

\section{Selectivity of glauconite at sorption of metal cations from water solutions in dynamic conditions}

\author{
Vigdorovich V.I. ${ }^{1,3}$, Tsygankova L.E. ${ }^{2}$, Alekhina O.V., ${ }^{2,3}$, Uryadnikova M.N. ${ }^{2}$, \\ Shel N.V. ${ }^{3}$, Zarapina I.V. ${ }^{3}$, Prokhorenkov V.D. ${ }^{1}$ \\ ${ }^{I}$ All-Russian Scientific Research Institute for the Use of Machinery and Oil Products, Tambov \\ ${ }^{2}$ Derzhavin State University, Tambov \\ ${ }^{3}$ Tambov State Technical University, Tambov
}

The selectivity of sorption on $95 \%$ glauconite concentrate at room temperature under dynamic conditions with respect to solutions of cation mixtures in two experimental series was studied. In each series, 
sorption was carried out from a single-component salt solution with the cation under study and a multicomponent system in the presence of salts of all cations under study at the same concentrations simultaneously.

In the first series, $0.1 \mathrm{mM}$ sulphate solution of salts of cations (II) of metals of the iron group was used. In the second series, the $\mathrm{Ca}$ (II) and $\mathrm{Mg}$ (II) cations are 0.125 and $1.56 \cdot 10^{-2} \mathrm{mmol} / \mathrm{dm}^{3} \mathrm{Cu}$ (II). In the latter case, the concentration of $\mathrm{Cu}$ (II) corresponded to the maximum permissible for waters for cultural purposes. The linear velocity of the solution was 0.3 and $0.5 \mathrm{~m} / \mathrm{h}$ (laminar flow). The height of the sorbent layer is 0.5 and $1.5 \mathrm{~cm}$.

Iron (II) cations are selectively sorbed by glauconite, which is proved by the identity of the sorption parameters (the sorption coefficient dependence in time and the dynamic capacity of the sorbent in different periods of the process) from single- and three-component solutions. Co (II) cations are sorbed only on free adsorption centers (AC) in the absence of Fe (II) and Ni (II) cations. They can act as exchange cations with the introduction of $\mathrm{Fe}$ (II) and $\mathrm{Ni}$ (II) ions. $\mathrm{Cu}$ (II) cations are sorbed selectively at certain AC in the presence of repeatedly (8 times) exceeding concentrations of $\mathrm{Ca}$ (II) and $\mathrm{Mg}$ (II) cations. The presence of $\mathrm{Cu}$ (II) ions, in turn, does not affect the sorption capacity of hardness cations.

Keywords: sorption, glauconite, flux, active center, selectivity, cations, iron, cobalt, nickel, calcium, magnesium, copper.

\section{Введение}

Относительная сорбционная способность сорбента по отношению к катионам металлов, выступающих в качестве сорбатов, одновременно присутствующих в стационарном растворе или в потоке жидкой фазы, может рассматриваться с нескольких точек зрения [1-4].

1. Как результат различной скорости сорбции частиц сорбата на единых активных центрах (АЦ), в том числе и занятых обменными катионами.

2. Как результат различной сорбционной способности, обусловленной наличием АЦ, различающихся энергетически и способных в силу этого частично сорбировать катионы различной природы. В частности, такая особенность АЦ может привести к появлению рядов катионов, по ходу которых происходит последовательное снижение или, напротив, возрастание селективной емкости сорбента. Например, согласно [1], на каолините при сорбции из однокомпонентных растворов (соль одного металла) по сорбционной способности установлен ряд: $\mathrm{Cd}(\mathrm{II})>\mathrm{Pb}(\mathrm{II})>\mathrm{Zn}$ (II) $>\mathrm{Cu}$ (II). B случае многокомпонентных растворов (одновременное присутствие всех указанных катионов) ряд несколько видоизменяется: $\mathrm{Cd}(\mathrm{II})>\mathrm{Zn}(\mathrm{II})>\mathrm{Pb}(\mathrm{II})>\mathrm{Cu}$ (II).

На глауконите в Na-форме в нитратных средах по удельной адсорбции наблюдается ряд [5]: $\mathrm{Ni}(\mathrm{II})>\mathrm{Zn}(\mathrm{II})>\mathrm{Cu}(\mathrm{II})$. Сорбционная способность сорбентов может зависеть и от природы обменных катионов. Например, на глауконите, сорбирующем с удалением обменных катионов, различной природы, сорбционная способность $\mathrm{Cu}(\mathrm{II})$ возрастает в ряду [6]: Li-форма> Na-форма>K-форма.

3. Возможна селективность сорбента, обусловленная тем, что его АЦ избирательно сорбируют катионы только одного вида. Подобная картина наблюдалась, в частности, на глауконите при удалении из жидкой фазы катионов (II) металлов группы железа, когда кинетика сорбции ионов $\mathrm{Ni}$ (II) и динамическая емкость сорбента оказалась одинаковой при адсорбции из однокомпонентных $\left(\mathrm{NiSO}_{4}\right)$ и многокомпонентных $\left(\mathrm{NiSO}_{4}, \mathrm{FeSO}_{4}\right.$ и $\left.\mathrm{CoSO}_{4}\right)$ растворов при постоянстве исходной концентрации сорбата [7].

Точно такая же картина характерна для катионов $\mathrm{Ni}(\mathrm{II})$ при сорбции их из хлоридных растворов в присутствии многократно превышающих концентраций ионов $\mathrm{Ca}(\mathrm{II})$ и $\mathrm{Mg}(\mathrm{II})$ [7].

Последний случай представляет значительный практический интерес. Он позволяет с одинаковой эффективностью проводить сорбционную очистку от сорбатов одной и той же природы как в случае многокомпонентных растворов, так и однокомпонентных сред, направляемых в адсорбер последовательно. Так, стоки гальва- 
нических производств процессов железнения, никелирования и кобальтирования металлических поверхностей, по-видимому, можно очищать от катионов металлов (II) группы железа посредством сорбции на глауконите, собирая их предварительно в единых накопительных емкостях или направляя последовательно в адсорберы из различных накопителей сточной воды, содержащей сорбат только одной природы. Та же картина характерна и для очистки стоков участков никелирования, сопровождаемых последовательным или параллельным умягчением воды.

Целью настоящей работы явилось изучение избирательности сорбции на глауконите катионов (II) металлов группы железа (растворы серии 1) и меди (II) из сред с существенно превышающим содержанием ионов Сa(II) и $\mathrm{Mg}$ (II) (растворы серии 2).

\section{Эксперимент}

Сорбент, в качестве которого использован 95\%-ный концентрат глауконита Бондарского месторождения (ТУ-2164-002-03039858-08), подвергался предварительной обработке, согласно [7]. Сорбцию катионов группы железа проводили из сульфатных растворов соответствующих солей при 0.1 мМ исходной концентрации. Ионы $\mathrm{Cu}(\mathrm{II})$ сорбировали из хлоридных растворов с начальной концентрацией солей, содержащих катионы щелочно-земельных металлов - 0,125 ммоль/дм ${ }^{3}, \mathrm{CuCl}_{2}$ $1.56 \cdot 10^{-2}$ ммоль/дм ${ }^{3}$, что близко к предельно-допустимой концентрации меди в воде хозяйственно-бытового назначения (1 мг/дм $\left.{ }^{3}[8]\right)$.

Сорбцию проводили в динамическом режиме с линейной скоростью растворов 0.3 и 0.5 м/ч при высоте слоя сорбента 0.5 или 1.5 см. Концентрацию катионов жесткости в заданные моменты времени оценивали комплексометрически [9], остальных катионов посредством рентгенофлуоресцентного анализа (спектрометр «Спектроскан - МАКC-GV»). Степень извлечения катионов сорбентом определяли при комнатной температуре посредством коэффициента сорбции $\rho$, рекомендуемого $[3,4]$ и выражаемого зависимостью, $\rho=\left(\mathrm{C}_{0}-\mathrm{C}_{\mathrm{i}} / \mathrm{C}_{0}\right)$, т.е. представляющего собой отношение разности концентраций катионов в исходном растворе $\left(\mathrm{C}_{0}\right)$ и в среде в данный момент времени и (или) по завершению эксперимента $\left(\mathrm{C}_{\mathrm{i}}\right)$ к их начальной величине. Ошибка в определении $\rho$ не превышала $2 \%$.

\section{Обсуждение результатов}

Сорбция катионов растворов I-й серии. Влияние продолжительности сорбции и линейной скорости потока жидкой фазы на величину коэффициента адсорбции катионов $\mathrm{Fe}(\mathrm{II})$ при высоте слоя сорбента $\mathrm{h}=0.5$ см из одно- и трехкомпонентных (ионы $\mathrm{Fe}(\mathrm{II}), \mathrm{Co}(\mathrm{II})$ и $\mathrm{Ni}(\mathrm{II})$ находятся одновременно в равных исходных концентрациях) растворов показано на рис. 1.

При линейной скорости потока 0.3 м/ч в первые 20 минут присутствие одновременно всех типов ионов никак не сказывается на величине $\rho$, близкой к $100 \%$. Этот эффект возможен в двух случаях. Либо активные центры (АЦ) глауконита избирательно сорбируют различные катионы и тогда присутствие катионов Со(II) и $\mathrm{Ni}$ (II) не сказывается на величине $\rho_{\mathrm{Fe}(\mathrm{II})}$. Или динамическая емкость сорбента столь велика, что на АЦ сорбируются все катионы, тогда селективность АЦ глауконита не проявляется. Установление определяющей роли первого или второго фактора может быть достигнуто увеличением продолжительности сорбции, когда концентрация АЦ может оказаться недостаточной для полного извлечения $\mathrm{Fe}(\mathrm{II})$ из раствора, содер-

$\boldsymbol{B}$ игдорович и др. / Сорбционные и хроматографические процессы. 2018. Т. 18. № 5 
жащего все три типа катионов металлов группы железа. Действительно, в последующие 20 минут сорбции (рис. 1, фрагменты гистограммы (ФГ) 3 и 4) величина $\rho_{\mathrm{Fe}(\mathrm{II})}$ становится меньше $100 \%$. При этом величина $\rho_{\mathrm{Fe}(\mathrm{II})}$ из трехкомпонентного раствора даже несколько больше, чем из однокомпонентного, это указывает на определяющую роль фактора селективности АЦ. В последующие 20 минут (рис. 1, ФГ 5 и 6) картина остается практически без изменения в пределах ошибки эксперимента, что можно считать косвенным подтверждением решающего вклада селективности АЦ.

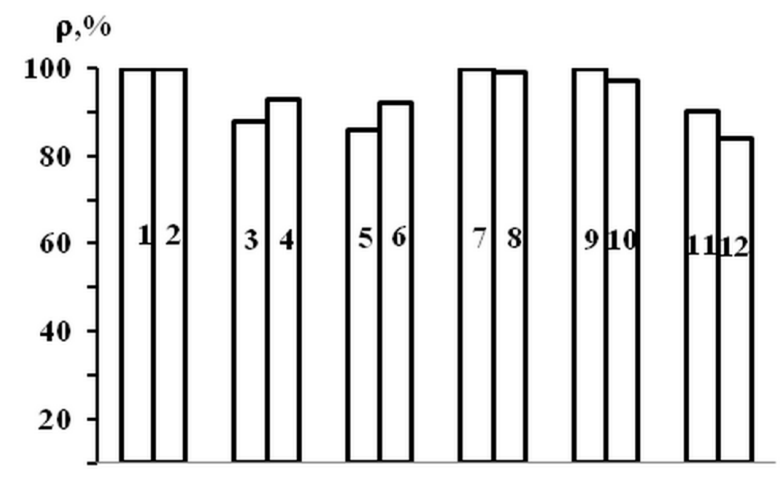

Рис. 1. Влияние продолжительности сорбции на величину коэффициента $\rho$ катионов $\mathrm{Fe}(\mathrm{II})$ из сульфатных растворов. Исходная концентрация всех катионов 0.1 ммоль/дм ${ }^{3}$, высота слоя сорбента -0.5 см. Нечетные цифры на элементах гистограммы - однокомпонентный раствор $\mathrm{FeSO}_{4}$, четные - трехкомпонентный $\left(\mathrm{FeSO}_{4}+\mathrm{CoSO}_{4}+\mathrm{NiSO}_{4}\right)$. Время от начала сорбции, мин: $1,2,7$ и $8-20 ; 3,4,9$ и $10-$ $40 ; 5,6,11$ и 12 - 60. Линейная скорость потока раствора, м/ч: $1 \ldots 6-0.3 ; 7 \ldots 12-0.5$.

При повышении линейной скорости $v$ потока до 0.5 м/ч первые 20 минут сорбции величина $\rho_{\mathrm{Fe}(\mathrm{II})}$ из растворов различного компонентного состава вновь близка к 100\%. В последующие 20 минут (рис. 1, ФГ 9 и 10) на 2.5\% уменьшается величина $\rho_{\mathrm{Fe}(\mathrm{II})}$ из трехкомпонентного раствора, т.е. различия в коэффициенте сорбции $\rho_{\mathrm{i}}$ невелики. В последний 20-минутный интервал (рис. 1,ФГ 11 и 12) установлено понижение $\rho_{\mathrm{Fe}(\mathrm{II})}$ как из одно- (ФГ 11) так и из трехкомпонентного (ФГ 12) растворов. Причем в последнем случае $\rho_{\mathrm{Fe}(\mathrm{II})}$ ниже на $6 \%$ (рис. 1 , ФГ 11 и 12). Полученные данные можно, в первом приближении, рассматривать как подтверждение наличия селективности некоторой доли АЦ при учете их возможной энергетической неоднородности. В дальнейших экспериментах была увеличена высота слоя сорбента в три раза при прочих неизменных условиях (рис. 2).

В этом случае при линейной скорости потока раствора $v$, равной 0.3 м/ч, в первые 20 минут сорбции величина $\rho_{\mathrm{Fe}(\mathrm{II})}$ из трехкомпонентного раствора в пределах чувствительности анализа была близка к $100 \%$, а из однокомпонентного раствора на $3 \%$ ниже (рис. 2, ФГ 1 и 2). Данный факт, конечно, не может быть обусловлен селективностью АЦ. Для двух последующих 20-минутных интервалах сорбции катионов $\mathrm{Fe}(\mathrm{II})$ (рис. 1, ФГ 3 и 4; 5 и 6) наблюдалась аналогичная зависимость. Различие состояло лишь в том, что величина $\rho_{\mathrm{Fe}(\mathrm{II})}$ из однокомпонентного раствора понижалась на 7-8\%. При линейной скорости потока до 0,5 м/ч $\Delta \rho_{\mathrm{Fe}(\mathrm{II})}$ в двух последних 20-ти минутных интервалах уменьшилось до 3-5\%. При этом $\rho_{\mathrm{Fe}(\mathrm{II})}$ из трехкомпонентного раствора (рис. 2, ФГ 10 и 12) был выше, чем из однокомпонентного (рис. 2, ФГ 9 и $11)$. 


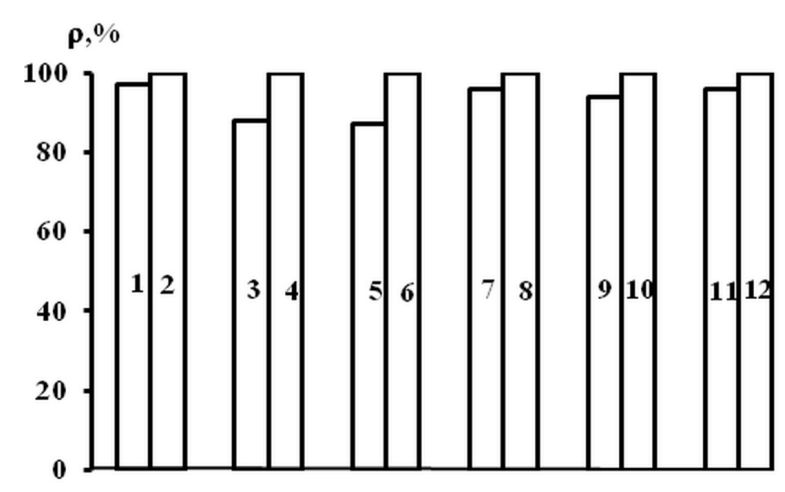

Рис. 2. Влияние продолжительности сорбции на величину коэффициента адсорбции катионов $\mathrm{Fe}(\mathrm{II})$ из сульфатных растворов. Исходная концентрация всех катионов - 0.1 ммоль/дм ${ }^{3}$, высота слоя сорбента -1.5 см. Нечетные цифры на элементах гистограммы - однокомпонентный раствор $\mathrm{FeSO}_{4}$, четные - трехкомпонентный $\left(\mathrm{FeSO}_{4}+\mathrm{CoSO}_{4}+\mathrm{NiSO}_{4}\right)$. Время от начала сорбции, мин: $1,2,7$ и $8-20 ; 3,4,9$ и $10-$ $40 ; 5,6,11$ и 12 - 60. Линейная скорость потока раствора, м/ч: $1 \ldots 6-0.3 ; 7 \ldots 12-0.5$.

Подобные данные можно интерпретировать как результат наличия высокой избирательности АЦ при синергетическом влиянии катионов $\mathrm{Co}$ (II) и $\mathrm{Ni}$ (II) на сорбционную способность $\mathrm{Fe}(\mathrm{II})$, например, за счет изменения ионной силы раствора и соответственно коэффициента активности $\mathrm{Fe}(\mathrm{II})$.

Влияние изученных факторов на сорбцию глауконитом катионов $\mathrm{Co}$ (II) существенно изменяется. При h и $v$, равных соответственно 0.5 см и 0.3 м/ч, уже в первые

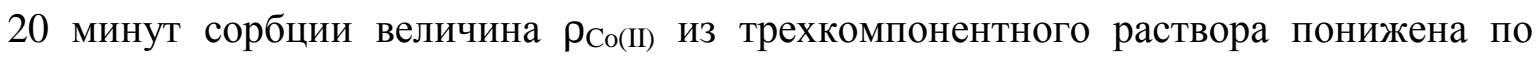
сравнению с $\rho_{\text {Со(II) }}$ из однокомпонентной среды на $6 \%$ (рис. 3, ФГ 1 и 2).

В последующие два 20-ти минутные интервала сорбции $\rho_{\text {Со(II) }}$ из трехкомпонентного раствора снижается до 70-71\%, тогда как для однокомпонентного раствора остается на уровне $\sim 100 \%$ (рис. 3, ФГ 3...6).

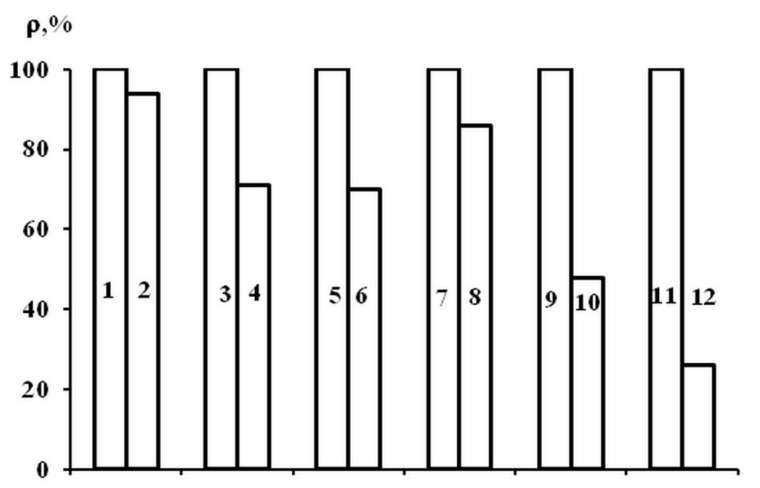

Рис. 3. Влияние продолжительности сорбции на величину коэффициента адсорбции катионов Со(II) из сульфатных растворов. Исходная концентрация всех катионов - 0.1 ммоль/дм ${ }^{3}$, высота слоя сорбента -0.5 см. Нечетные цифры на элементах гистограммы - однокомпонентный раствор $\mathrm{CoSO}_{4}$, четные - трехкомпонентный $\left(\mathrm{FeSO}_{4}+\mathrm{CoSO}_{4}+\mathrm{NiSO}_{4}\right)$. Время от начала сорбции, мин: $1,2,7$ и $8-20 ; 3,4,9$ и $10-$ 40; 5, 6, 11 и 12 - 60. Линейная скорость потока раствора, м/ч: $1 \ldots 6-0.3 ; 7 \ldots 12-0.5$.

С ростом линейной скорости потока до 0.5 м/ч различие в величинах $\rho_{\mathrm{Co}(\mathrm{II})}$ при сорбции из одно- и трехкомпонентных растворов становится значительно больше. Если величины $\rho_{\text {Со(II) }}$ из однокомпонентной среды в течение всего времени процесса сорбции остаются близкими к $100 \%$, то в случае трехкомпонентных растворов 
они снижаются на 14, 52 и 74\% соответственно в первом и последующих 20-ти минутных интервалах. Создается впечатление, что для катионов Сo(II) селективность АЦ выражена слабо или вообще отсутствует (рис. 3, ФГ 7-12).

Повышение высоты слоя сорбента в 3 раза не позволило получить дополнительную информацию, так как $\rho_{\text {Со(II) }}$ во всех случаях было близко к $100 \%$, т.е. концентрация АЦ была достаточной для сорбции всех катионов Со(II) из раствора и конкуренция за них между катионами $\mathrm{Fe}(\mathrm{II}), \mathrm{Co}(\mathrm{II})$ и $\mathrm{Ni}(\mathrm{II})$ отсутствовала.

В таблицах 1 и 2 обобщены данные по оценке динамической емкости (Q) катионов $\mathrm{Fe}(\mathrm{II})$ и $\mathrm{Co}$ (II) как функции продолжительности процесса сорбции, линейной скорости потока раствора и высоты слоя сорбента. Такой подход позволяет сопоставить влияние этих факторов на Q сорбента при протекании через сорбент одно- и трехкомпонентных растворов, а также высказать предположение об отсутствии или наличии селективности АЦ.

Таблица 1. Динамическая емкость Q глауконита при сорбции $\mathrm{Fe}(\mathrm{II})$. Числитель $\mathrm{h}=0.5 \mathrm{~cm}$, знаменатель $\mathrm{h}=1.5 \mathrm{~cm}$.

\begin{tabular}{|c|c|c|c|c|c|c|c|}
\hline \multirow{3}{*}{\multicolumn{2}{|c|}{$\begin{array}{c}\text { Фактор } \\
\text { Интервал времени от нача- } \\
\text { ла сорбции, мин }\end{array}$}} & \multicolumn{6}{|c|}{$\mathrm{Q} \cdot 10^{3}$, ммоль $/ \Gamma$} \\
\hline & & \multicolumn{2}{|c|}{$0-20$} & \multicolumn{2}{|c|}{$20-40$} & \multicolumn{2}{|c|}{$40-60$} \\
\hline & & $\mathrm{K}_{1}^{*}$ & $\mathrm{~K}_{3}$ & $\mathrm{~K}_{1}$ & $\mathrm{~K}_{3}$ & $\mathrm{~K}_{1}$ & $\mathrm{~K}_{3}$ \\
\hline \multirow{4}{*}{$\begin{array}{c}\text { Линейная ско- } \\
\text { рость потока, } \\
\text { м/ч: }\end{array}$} & \multirow{2}{*}{0.3} & 1.67 & 1.66 & 1.47 & 1.56 & 1.46 & 1.56 \\
\hline & & 0.34 & 0.35 & 0.31 & 0.35 & 0.31 & 0.35 \\
\hline & \multirow{2}{*}{0.5} & 2.78 & 2.75 & 2.79 & 2.70 & 2.50 & 2.33 \\
\hline & & 0.49 & 0.62 & 0.59 & 0.62 & 0.61 & 0.62 \\
\hline
\end{tabular}

$\mathrm{K}_{1}^{*}$ - в растворе только $\mathrm{Fe}(\mathrm{II}), \mathrm{K}_{3}$ - в растворе одновременно $\mathrm{Fe}(\mathrm{II}), \mathrm{Co}(\mathrm{II})$ и $\mathrm{Ni}(\mathrm{II})$.

Таблица 2. Динамическая емкость Q глауконита при сорбции Сo(II). Числитель $\mathrm{h}=0.5 \mathrm{~cm}$, знаменатель $\mathrm{h}=1.5 \mathrm{~cm}$.

\begin{tabular}{|c|c|c|c|c|c|c|c|}
\hline \multirow{3}{*}{\multicolumn{2}{|c|}{$\begin{array}{c}\text { Фактор } \\
\text { Интервал времени } \\
\text { от начала сорбции, мин }\end{array}$}} & \multicolumn{6}{|c|}{$\mathrm{Q} \cdot 10^{3}$, ммоль/Г } \\
\hline & & \multicolumn{2}{|c|}{$0-20$} & \multicolumn{2}{|c|}{$20-40$} & \multicolumn{2}{|c|}{$40-60$} \\
\hline & & $\mathrm{K}_{1}^{*}$ & $\mathrm{~K}_{3}$ & $\mathrm{~K}_{1}$ & $\mathrm{~K}_{3}$ & $\mathrm{~K}_{1}$ & $\mathrm{~K}_{3}$ \\
\hline \multirow{4}{*}{$\begin{array}{c}\text { Линейная ско- } \\
\text { рость потока, } \\
\text { м/ч: }\end{array}$} & \multirow{2}{*}{0.3} & 1.65 & 1.60 & 1.64 & 1.20 & 1.65 & 1.20 \\
\hline & & 0.33 & 0.36 & 0.35 & 0.36 & 0.34 & 0.35 \\
\hline & \multirow[b]{2}{*}{0.5} & 2.75 & 2.40 & 2.75 & 1.32 & 2.75 & 0.70 \\
\hline & & 0.62 & 0.63 & 0.62 & 0.63 & 0.62 & 0.63 \\
\hline
\end{tabular}

$\mathrm{K}_{1}^{*}$ - в растворе только Со(II), $\mathrm{K}_{3}$ - в растворе одновременно $\mathrm{Fe}(\mathrm{II})$, Сo(II) и $\mathrm{Ni}(\mathrm{II})$.

В случае сорбции катионов $\mathrm{Fe}(\mathrm{II})$ качественно картина не отличается от наблюдаемой ранее для $\mathrm{Ni}$ (II) [7]. При v, равной 0.3 м/ч, и используемых высотах слоя сорбента динамическая емкость глауконита из одно- и трехкомпонентных растворов практически одинакова (таблица 1) и несколько снижается с ростом продолжительности сорбции. Причем в интервалах больших времен она даже несколько выше в случае трехкомпонентных сред, хотя можно было ожидать обратной тенденции в результате конкуренции катионов различной природы за адсорбционные центры (АЦ). Установленные различия, очевидно, обусловлены погрешностью эксперимента. Снижение Q с ростом продолжительности сорбции обусловлено уменьшением концентрации АЦ во времени.

Подобная картина наблюдается и при линейной скорости потока раствора 0.5 м/ч. Причем отношение $\mathrm{Q}_{0.5} / \mathrm{Q}_{0.3}$ (нижний индекс характеризует величину v) близко к отношению используемых величин v. Эти данные позволяют предполагать, что катионы $\mathrm{Fe}(\mathrm{II})$ селективно сорбируются строго определенными АЦ, а ионы $\mathrm{Ni}$ (II) 
и Сo(II) в этом случае не являются конкурентоспособными. Для катионов Со(II) картина несколько иная (таблица 2.).

Динамическая емкость глауконита остается неизменной во времени при высоте слоя $\mathrm{h}=1.5 \mathrm{~cm}$. С уменьшением $\mathrm{h}$ до 0.5 см величина $\mathrm{Q}_{\mathrm{i}}$ для катионов $\mathrm{Co}(\mathrm{II})$ из трехкомпонентных растворов снижается с ростом времени сорбции. Следовательно, начиная с определенной доли свободных АЦ (а энергетика таких АЦ, как можно предположить, заметно различается), катионы $\mathrm{Fe}(\mathrm{II})$ и $\mathrm{Ni}(\mathrm{II})$, либо одни из них, конкурируют с $\mathrm{Co}$ (II) за обменные катионы $\mathrm{Na}^{+}$, что ведет к понижению Q(Co(II)). Причина уменьшения $\mathrm{Q}_{\mathrm{i}}$ с повышением величины $\mathrm{h}$ (таблицы 1 и 2) пока не ясна. B первом приближении, это может быть вызвано ростом слипания частиц сорбента с увеличением высоты слоя сорбента.

Сорбция катионов, находящихся в растворах серии II. Дополнительно изучена сорбция катионов $\mathrm{Cu}(\mathrm{II})$ в присутствии многократно превышающих (8 раз) концентраций $\mathrm{Ca}(\mathrm{II})$ и $\mathrm{Mg}(\mathrm{II})$ (рис. 4 и 5).

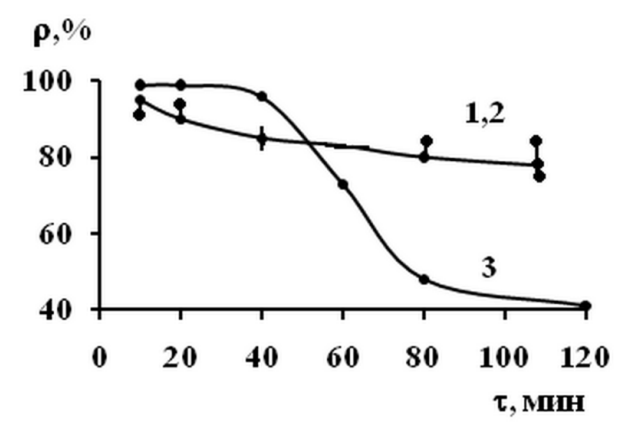

Рис. 4. Кинетические кривые сорбции катионов $\mathrm{Ca}(\mathrm{II})(1,2)$ и $\mathrm{Cu}(\mathrm{II})$ глауконитом в отсутствие (1) и в присутствии (2) катионов $\mathrm{Cu}(\mathrm{II})$; (3) - $\mathrm{Cu}(\mathrm{II})$ в присутствии $\mathrm{Ca}(\mathrm{II})$

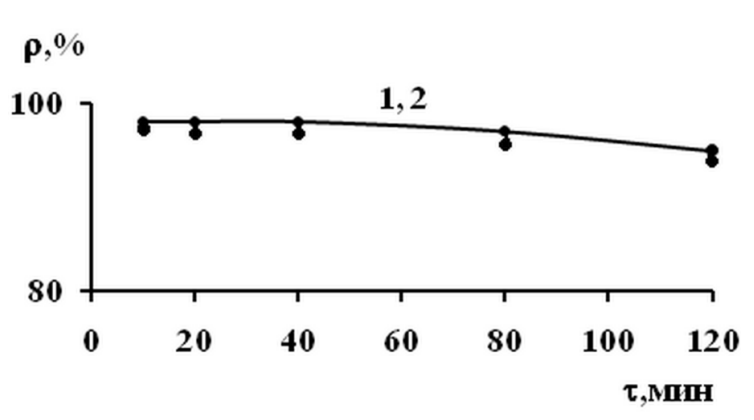

Рис. 5. Кинетические кривые сорбции катионов $\mathrm{Mg}(\mathrm{II})$ глауконитом в отсутствие (1) и в присутствии (2) в растворе катионов $\mathrm{Cu}(\mathrm{II})$

Как следует из полученных результатов, катионы $\mathrm{Ca}(\mathrm{II})$ (рис. 4) и $\mathrm{Mg}$ (II) (рис. 5) сорбируются глауконитом в отсутствие $\mathrm{Cu}$ (II) уже за первые 20 минут соответственно на 90 и 98\%. Присутствие в растворе катионов $\mathrm{Cu}(\mathrm{II})$ не влияет на величину $\rho_{\mathrm{Ca}(\mathrm{II})}$ и $\rho_{\mathrm{Mg}(\mathrm{II})}$. В свою очередь, катионы $\mathrm{Cu}$ (II) первые 40 минут процесса сорбируются практически полностью (рис. 4), затем величина $\rho_{\mathrm{Cu}(\mathrm{II})}$ существенно снижается, видимо, в силу исчерпания в значительной мере динамической емкости. Можно сделать вывод, что активные центры, сорбирующие катионы $\mathrm{Cu}(\mathrm{II})$, селективны и не сорбируют $\mathrm{Ca}(\mathrm{II})$ и $\mathrm{Mg}(\mathrm{II})$, несмотря на их многократно превышающую концентрацию. В свою очередь, наличие $\mathrm{Cu}(\mathrm{II})$ не сказывается на эффективности сорбции глауконитом катионов жесткости.

\section{Заключение}

На глауконите катионы $\mathrm{Fe}(\mathrm{II})$ избирательно сорбируются на активных центрах, на которых сорбция $\mathrm{Co}(\mathrm{II})$ и $\mathrm{Ni}(\mathrm{II})$ в их присутствии затруднена. На другой группе АЦ в присутствии $\mathrm{Fe}(\mathrm{II})$ и Со(II) избирательно сорбируются только катионы $\mathrm{Ni}(\mathrm{II})$. Для катионов $\mathrm{Co}(\mathrm{II})$ при одновременной сорбции на глауконите $\mathrm{Fe}(\mathrm{II})$ и $\mathrm{Ni}$ (II) специфических активных центров не существует. Катионы Со(II) сорбируются на любых оставшихся свободными активных центрах при полной сорбции $\mathrm{Fe}(\mathrm{II})$ и $\mathrm{Ni}(\mathrm{II})$. Но они должны вытесняться с них, как это происходит с обменными катиона- 
ми $\mathrm{Na}^{+}$, при дополнительном введении в раствор катионов железа (II) и никеля (II). Ионы $\mathrm{Cu}(\mathrm{II})$ при присутствии в растворе катионов $\mathrm{Ca}(\mathrm{II})$ и $\mathrm{Mg}$ (II) в многократно превышающих концентрациях избирательно сорбируются на определенных АЦ.

\section{Исследование выполнено за счет гранта Российского научного фонда (проект № 18-16-00066)}

\section{Список литературы}

1. Eginary D.E., Baker A.R., Andrews J.E. // J. Coll. Interface Sci. 2005. Vol. 291. No 2. pp. 319-325.

2. Malamis S., Katsou E. // J. Hazardous Materials. 2013. Vol. 252-253. pp. 428-461.

3. Vieira M.G.A., Almeida Neto A.F., Grimens M.L., da Silva M.G.C. // Hazardous Materials. 2010. Vol. 176. No 2. pp. 109-118.

4. Almeida Neto A.F., Vieira M.L. M.G.A., Silva M.G.K. // J.' Water process engineering. 2014. Vol. 3. No 1. pp. 90-97.

5. Вигдорович В.И., Жуковская Т.В., Цыганкова Л.Е., Урядникова М.Н., Шель Н.В. // Конденсированные среды и межфразные гранииьы. 2018. Т. 20. № 1. С. 32-41.

\section{References}

1. Egirany D.E., Baker A.R., Andrews J.E., J. Coll. Interface Sci, 2005, Vol. 291, No 2, pp. 319-325.

2. Malamis S., Katsou E., J. Hazardous Materials, 2013, Vol. 252-253, pp. 428-461.

3. Vieira M.G.A., Almeida Neto A.F., Grimens M.L., da Silva M.G.C., Hazardous Materials, 2010, Vol. 176, No2, pp. 109-118.

4. Almeida Neto A.F., Vieira M.L. M.G.A., Silva M.G.K., J.' Water process engineering, 2014, Vol. 3, No 1, pp. 90-97.

5. Vigdorovich V.I., Zhukovskaya T.V., Tsygankova L.E., Uryadnikova M.N. et al., Kondensirovannye sredy $i$ mezhfaznye granitsy, 2018, Vol. 20, No 1, pp. 32-41.

Вигдорович Владимир Ильич - д.Х.Н., проф., академик РАЕН, заслуженный деятель науки и техники РФ, главный научный сотрудник ВНИИТиН, профессор Тамбовского государственного технического университета (по совместительству). Тамбов, Тел./ факс: (8 4752)44-64-14

Цыганкова Людмила Евгеньевна - д.х.н., проф., академик РАЕН, зав. кафедрой химии и экологической безопасности Тамбовского государственного университета имени Г.Р. Державина, Тамбов
6. Григорьева Е.А. Автореферат дис... канд. хим. наук. Челябинск. 2004. 18 с.

7. Вигдорович В.И., Цыганкова Л.Е., Алехина О.В., Урядникова М.Н. // Сорбционные и хроматографические прочессы. 2018. Т. 18. № 1. C. 35-42.

8. Вишняков Я.Д., Бурцева Н.Н., Киселева С.П., Рыков С.В. и др. Нормирование и снижение загрязнения окружающей среды. М. Академия. 2015. 386 с.

9. Отто М. Современные методы аналитической химии. Под редакцией А.В. Гармаша М. Техносфера. 2008. 544 с.

6. Grigoreva Ye.A., Avtoreferat dis... kand. khim. nauk. Chelyabinsk, 2004, 18 p.

7. Vigdorovich V.I., Tsygankova L.E., Alekhina O.V., Uryadnikova M.N., Sorbtsionnye $i$ khromatograficheskie protsessy, 2018, Vol. 18, No 1, pp. 35-42.

8. Vishnyakov YA.D., Burceva N.N., Kiseleva S.P., Rykov S.V. et al., Normirovanie i snizhenie zagryazneniya okruzhayushchej sredy. M., Akademiya, 2015, 386 p.

9. Otto M. Sovremennye metody analiticheskoy khimii / Pod redaktsiey A.V. Garmasha. M., Tekhnosfera, 2008, 544 p.

Vigdorovich Vladimir I. - Doctor of Chemical Sciences, Professor, Academician of the Russian Academy of Natural Sciences, Honored Worker of Science and Technology of the Russian Federation, Chief Scientific Officer of VNIITiN, Professor of Tambov State Technical University in combination, Tambov, e-mail: vits21@mail.ru

Tsygankova Liudmila E. - doctor of chemical sciences, professor, Academician of the Russian Academy of Natural Sciences, Head of the Department of Chemistry and Ecological Safety of Tambov State University named after G.R. Derzhavin, Tambov 
Алехина Ольга Владимировна - к.х.н., доцент кафедры химии и экологической безопасности, Тамбовский государственный университет имени Г.Р. Державина, Тамбов

Урядникова Марина Николаевна - к.Х.н., старший преподаватель кафедры химии и экологической безопасности, Тамбовский государственный университет имени Г.Р. Державина, Тамбов

Шель Наталья Владимировна - д.х.н., профессор кафедры «Химия и химические технологии» Тамбовского государственного технического университета, Тамбов

Зарапина Ирина Вячеславовна - к.Х.н., доцент кафедры «Химия и химические технологии» Тамбовского государственного технического университета, Тамбов

Прохоренков Вячеслав Дмитриевич д.т.н., главный научный сотрудник ВНИИТиН, Тамбов
Alekhina Olga V. - Candidate of Chemistry, Associate Professor of the Department of Chemistry and Environmental Safety, Tambov State University named after GR. Derzhavin, Tambov

Uryadnikova Marina N. - Candidate of Chemistry, senior lecturer of the Department of Chemistry and Environmental Safety, Tambov State University named after G.R. Derzhavin, Tambov

Shel Natalia V. - Doctor of Chemical Sciences, Professor of the Department "Chemistry and Chemical Technologies" of Tambov State Technical University, Tambov

Zarapina Irina V. - Candidate of Chemistry, Associate Professor of the Department "Chemistry and Chemical Technologies" of Tambov State Technical University, Tambov

Prokhorenkov Vyacheslav D. - doctor of technical sciences, Chief Scientific Officer of VNIITiN, Tambov 